\title{
GRUPO DE TRABALHO DE ENSINO INVESTIGATIVO: UM PROCESSO DE CONSTRUÇÃO E CONTRIBUIÇÃO PARA A FORMAÇÃO DOCENTE
}

\section{GROUP OF RESEARCH TEACHING WORK: A CONSTRUCTION AND CONTRIBUTION PROCESS FOR TEACHER TRAINING}

Janikelle Maciel da Silva ${ }^{1}$; Wilson Antonio da Silva ${ }^{2}$, Renata Joaquina de Oliveira Barboza ${ }^{3}$; Fernando Cleyton Henrique de Mendonça Silva ${ }^{4}$; Kilma da Silva Lima Viana ${ }^{5}$

\section{INTRODUÇÃO}

Um dos grandes desafios para os docentes é a busca por novas metodologias para o processo de ensino-aprendizagem que viabilizem a quebra de paradigmas de uma sociedade marcada pelo ensino tradicional. A prática docente baseada apenas em aulas teóricas e expositivas, em sua maioria não é mais suficiente para as demandas da educação atual, fazendo com que outras metodologias de ensino se façam necessárias para contribuir efetivamente na construção de conhecimento dos estudantes.

Neste sentido, o Ensino Investigativo surge como um método que propõe estimular o aluno a refletir, pensar, questionar e discutir acerca dos conteúdos em sala de aula, por meio de situações problemas trazidas pelo professor. Nesta perspectiva, consideramos a Sequência de Ensino Investigativo (SEI) que valoriza o aluno como foco deste sistema, segundo Foutura (2017), faz com que o mesmo tenha a iniciativa de protagonizar seu próprio processo de aprendizagem, criar hipóteses e soluções para problemas reais.

\section{RELATO DE EXPERIÊNCIA}

O Grupo de trabalho de Ensino Investigativo é formado por estudantes em formação do curso de Licenciatura em Química do Instituto Federal de Educação, Ciência e Tecnologia de Pernambuco - IFPE-CVSA e três coordenadores formados em licenciatura em química na mesma instituição, e busca realizar ações em escolas do Ensino Médio através do Programa Internacional despertando vocações para licenciatura (PDVL).

A atuação do Grupo de Trabalho (GT) de Ensino Investigativo desenvolve competências consideráveis necessárias para formação da carreira docente. O processo

\footnotetext{
${ }^{1}$ Graduanda em Licenciatura em Química, Instituto Federal de educação, ciência e tecnologia de Pernambuco - IFPE, kellemaciel18@gmail.com

${ }^{2}$ Graduando em Licenciatura em Química, Instituto Federal de educação, ciência e tecnologia de Pernambuco - IFPE, wilson.antonio98@ hotmail.com

3 Mestranda em Educação de Ciências e Matemática, Universidade Federal de Pernambuco - UFPE, renata_joaquina@hotmail.com

${ }^{4}$ Mestrando no PPGECM, Universidade Federal de Pernambuco - UFPE, silva.fchm@gmail.com

${ }^{5}$ Doutora em Ensino de Ciências, Instituto Federal de Pernambuco, kilma.viana@ vitoria.ifpe.edu.br
} 
construtivo consiste de intervenções em escolas parceiras do PDVL com foco na SEI, levando para as aulas um plano de sequência didática a partir de uma problemática, que preferencialmente esteja relacionado a um tema do meio social dos alunos. Bachelard (1938) quando propõe que "todo conhecimento é a resposta de uma questão" refere-se que não deve ser uma questão ou um problema qualquer, para ser importante para os alunos, deve estar dentro de sua cultura, sendo interessante para eles de modo que se envolva e procurem uma solução.

Dentro da SEI, além da problemática, temos a sistematização da atividade proposta, a contextualização e a avaliação do conhecimento construído. Segundo Carvalho (2013), o problema pode ser experimental ou teórico, contextualizado, que ofereça condições e induza os alunos a trabalharem as variáveis relevantes do conteúdo programado. Após a problemática, os estudantes levantam suas hipóteses iniciais para resolução do problema, e em seguida o professor inicia a atividade de sistematização, por meio de leituras, textos escritos, exposição do conteúdo, de forma que os estudantes possam comparar e discutir cientificamente a solução para o problema e reconstruir o pensamento inicial de suas hipóteses. Seguindo, temos a parte da contextualização do conhecimento, nesse momento eles podem associar os conhecimentos construídos ao ponto de vista social o qual estão inseridos. Por fim, é proposta uma atividade de avaliação, aplicada ao término ou durante todo o processo de execução de cada SEI.

Em todas as etapas, o foco principal é proporcionar aos alunos momentos que favoreçam a solução do problema levantado com propriedade científica e consequentemente a alfabetização científica dos mesmos. Assim, os pontos chaves dessa atividade é inovar, atrair e estimular os estudantes a construírem conhecimentos científicos. Dessa forma, o GT de Ensino Investigativo promove ações nas escolas para um ensino construtivista mais eficaz de aprendizagem em sala de aula.

Para isso, nas reuniões do GT sempre são discutidas o conhecimento teórico do Ensino Investigativo, juntamente com a prática da SEI promovida pelos coordenadores com os próprios integrantes do GT, com atividades como a experimentação, jogos didáticos e vídeos. Também são discutidas as atividades a serem realizadas nas escolas, assim como os problemas e conteúdos abordados nas intervenções, para que todos os participantes do GT possam contribuir positivamente nas atividades desenvolvidas. Assim, visto que a proposta geral é trabalhar a investigação em sala de aula, os participantes trabalham desta forma, com uma ideologia capaz de fazer e transformar o processo de ensino-aprendizagem. "Quando o professor leva o aluno, por meio de uma série de questões a tomar consciência de como o problema foi resolvido é porque deu certo, ou seja, a partir de suas próprias ações.” (CARVALHO, 2013). 


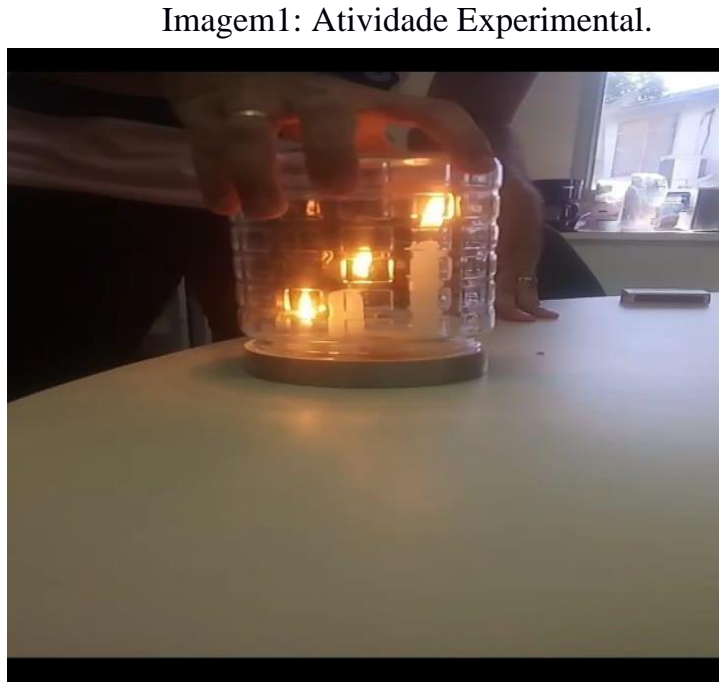

Fonte: Própria

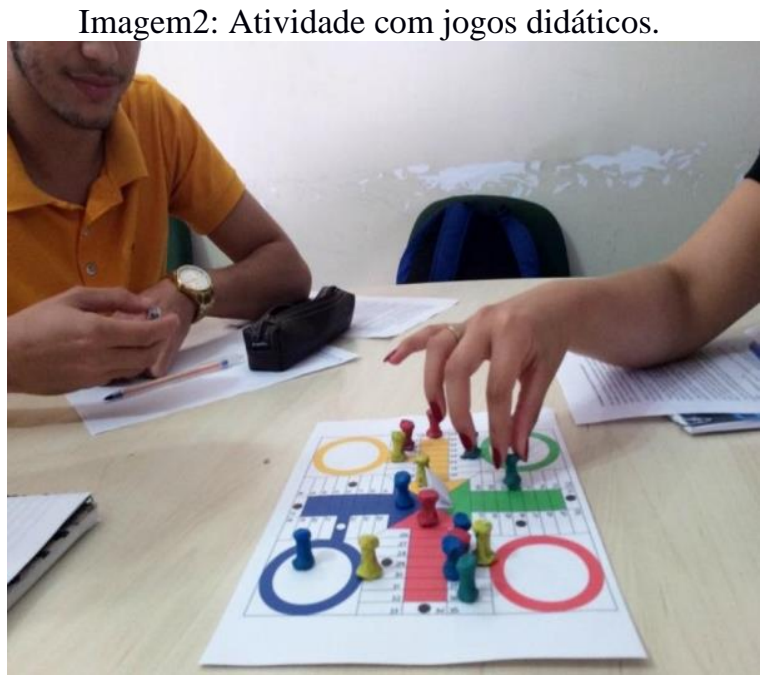

Fonte: Própria.

\section{CONSIDERAÇÕES}

Diante do exposto, é possível afirmar que por meio do Grupo de Trabalho de Ensino Investigativo junto ao PDVL, podemos enquanto professores em formação enriquecer e ampliar nossos conhecimentos metodológicos de ensino, adquirindo experiências do ser docente que serão valiosas para a aprendizagem dos estudantes, criando caminhos e métodos para todos aprenderem de forma eficaz. É por meio desta vivência, trabalhando com uma SEI que como futuros profissionais da educação construímos e valorizamos as atividades diferenciadas que possam expandir a qualidade de ensino-aprendizagem dos alunos e que permitem construir em toda sua potencialidade um conhecimento intelectual. As habilidades desenvolvidas a partir de uma metodologia investigativa não se adequa apenas para o ensino, defende Ponte (2003), tratase de uma capacidade de primeira importância para todos os cidadãos e que deveria permear todo o trabalho da escola, tanto dos professores como dos alunos.

\section{REFERÊNCIAS}

BACHELARD, G. La formation de l'espritscientifique.Paris: Vrin,1938.

CARVALHO, A. M. P. Ensino de ciências por investigação: Condições para implementação em sala de aula. São Paulo:Cengage Learning, 2013.

FOUTORA, J.Os desafios dos professores de ciência para implementar abordagem investigativa no ensino. Revista Educação, Dezembro de2017. Disponível em: 〈www.revistaeducacao.com.br〉. Acesso em: 06 out. 2018.

PONTE, J. P. M. Investigar, ensinar e aprender. Actas do ProfMat, 2003. Disponível em: <https://www.ime.usp.br/ brolezzi/disciplinas/20121/mat1500/investigar.pdf >. Acesso em: 18 out. $/ 2018$. 